must be used. Even so, counting-rates of 100 counts/ min. are rarely exceeded. Absolute intensity measurements are easier than with X-rays, since the scattering factor is independent of the scattering angle. In single-crystal work zero layer lines only are measured; in this type of work extinction corrections are generally considerable owing to the large crystals employed. Dr. W. Cochran briefly considered the use of counter methods for single-crystal X-ray measurements. Here overlapping spectra are not troublesome; lower resolution and lower accuracy of angle measurement are required than in powder work, and smaller spectrometer radii can thus be employed. Integrated reflexions can be measured conveniently by using a stationary crystal close to a very broad and uniform X-ray focus. Drs. Hirsch and Rieck pointed out the difficulty of obtaining the necessary uniformity of the focal spot.

The consideration of methods of identification by $\mathrm{X}$-ray crystallographic techniques was opened by Mr. H. S. Peiser, who pointed out how each problen requires different methods of approach. The enormous scope of X-ray identification methods justifies their use in nearly every manufacturing industry, for not only the constituents of a sample, but also their grain-size and nature, can often be identified by crystallographic methods.

Dr. D. M. C. McEwan described the special diffi. culties arising in the identification of clay minerals which may exist in the form of intimate mixtures on a molecular scale. Such structures can often be described only by their radial distributions. Frequently, the labile nature of clays causes line shifts to occur even with the simplest of preparatory treatments, and these shifts and the broadness of the bands render the standard card index inadequate. The most important information is often afforded by examining long spacings.

Special techniques are required in the identification of toxic and radioactive materials in order to safeguard the health of the operators and to prevent the fogging of the film. Some of these methods were described by Dr. J. Thewlis, who pointed out that in these cases minute quantities have to be used, the sample weighing less than a milligram. Photographic methods are employed, and the specimen is sealed in a capillary tube. With suitable precautions, samples having activities of several hundred microcuries can be photographed.

The most useful guide in the identification of most inorganic and some organic crystalline substances is the A.S.T.M. card index of lattice spacings, which now contains some five thousand cards, and the history of this index and of its continual growth and revision were related by Dr. A. J. C. Wilson, who has been in charge of the British part of this venture since 1942. A new type of index card is being produced which contains much more information than the old pattern. A set of 'Keysort' cards is now available, as are alphabetical and grouped indexes in book form. New and more accurate data are being substituted for the older information, spectrometers being used instead of powder cameras.

The need for supplementing information obtained from lattice spacings by other data was urged by Mr. R. Brooks. A consideration of the absorption of the sample, and of the type of fluorescent radiation it produces, often gives important clues, as do line broadening and the presence of preferred orientation. When single crystals are available axial lengths can be measured. Colour, refractive index, morphology and infra-red spectra may be of importance in addition to X-ray data.

Dr. K. W. Andrews said that he has found it more convenient at times to use one's own collection of known patterns than to employ the A.S.T.M. index for identification. In Mr. G. H. Cockett's experience, the use of lithium fluoride-reflected radiation is very valuable in identification problems, and he also makes frequent use of X-ray fluorescent analysis. Prof. $J$. D. Bernal suggested that the problems of analysis could be simplified by breaking up the complete A.S.T.M. index into groups of related substances; the weakest lines, the longest spacings, or 'Ionely lines' of a pattern are often more characteristic of a substance than the strongest line. Prof. E. G. Cox announced that he is investigating the best method of indexing single-crystal data for identification purposes.

A valuable feature of the conference was the unusually extensive exhibition. An informative and stimulating evening discourse was delivered by Dr. R. W. G. Wyckoff, whose subject was "A Survey of X-ray Diffraction in the United States". The next conference of the Group will be held in Cambridge during April 1-2, 1954, and will be devoted to modern structure analysis.

U. W. ARndt

\section{ANTIBIOTICS IN PIG FOOD}

TNTIL recently the use of antibiotics in animal feeds was prohibited in Great Britain; but the Penicillin Act, 1947, has now been amended by the Therapeutic Substances (Prevention of Misuse) Act, 1953 , and the Statutory Instrument 1953 No. 1174 Therapeutic Substances : The Therapeutic Substances (Supply of Antibiotics for Agricultural Purposes) Regulations, 1953-allows the use of aureomycin and penicillin in pig and poultry foods. The purpose of these additions is the improvement of growth of pigs and poultry under practical conditions, first observed in the United States ${ }^{1}$, where antibiotics have been used on a large scale as growth promoters for several years now. The Ministry of Agriculture has now issued Advisory Leaflet No. 418, "Antibiotics in Livestock Feeding" (H.M.S.O. 2d.).

In October 1951 the Agricultural Research Council called a meeting to decide whether the available findings justified the use of antibiotics in Britain. By that time, many American publications had confirmed the value of antibiotics; but British experimental evidence was still very limited ${ }^{2}$, and in view of the marked difference in British and American methods of pig feeding and management, further work here was thought necessary before a decision was taken. The Agricultural Research Council therefore organized further trials, which took place in 1952 , and $a$ summary of their results was published in July $1953^{3}$.

The trials, designed and analysed with the guidance of statisticians, were of two kinds. One was to determine the effect of antibiotic supplements on the growth-rate, efficiency of food conversion and carcass quality of fattening pigs, the other to measure their volue for suckling pigs.

Six research centres were asked to work with fattening pigs. They were: the Agricultural Research Council Field Station at Compton, the British Oil and Cake Mills, Ltd., Experimental Station at Stoke Mandeville, the Harper Adams Agricultural College, the National Agricultural Advisory Service Experi- 
mental Husbandry Farms at Terrington St. Clement and at Trawscoed, and the National Institute for Research in Dairying at Shinfield.

Two types of diet were used : one with white-fish meal and vegetable protein was typical of the diets mainly used for fattening pigs in Britain ; in the other the protein was of vegetable origin only. Both diets were tested in two systems of feeding, the usual all-meal system and the Lehmann system in which a constant daily quantity of a meal mixture is supplemented with a gradually increasing amount of home-grown bulky foods. The antibiotics tested were penicillin given as procaine penicillin, and aureomycin included as 'Aurofac $2 A$ ', the proprietary mixture containing also some vitamin $B_{12}$ made by Lederle Laboratories, Ltd. In most trials vitamin $B_{12}$ was also added to the penicillin supplements and the antibiotics were tested side by side. The antibiotic content of the diets varied with centres and experiments; with procaine penicillin it was usually at 15 or $43 \mathrm{gm}$./ton (equivalent to 9 or $27 \mathrm{gm}$. penicillin) and with aureomycin at 14 and $28 \mathrm{gm}$./ton.

In all but one centre the pigs were fed according to scales for fattening pigs. The experiments began within a few weeks of weaning and continued to bacon-weight, when the pigs were slaughtered and most of the carcasses were graded by an expert. The diversity of treatments and conditions make it impossible to discuss and consider them in detail ; but a clear view of the findings can be obtained from a study of the general conclusions of the report based on experiments with some five hundred pigs.

On the unsupplemented rations with animal protein, the mean daily live-weight gain was $1 \cdot 17 \mathrm{lb}$. (standard error \pm 0.013 ) ; with penicillin it was $1.29 \mathrm{lb}$. (S.E. $\pm 0 \cdot 013$ ) and with aureomycin $1.28 \mathrm{lb}$. (S.E. \pm 0.015$)$. On all-vegetable diets the figures were $1.05 \mathrm{lb} .(+0.020), 1.18 \mathrm{lb} .(+0.020)$ and 1.22 lb. $( \pm 0.022)$. Both antibiotics, therefore, improved the growth of fattening pigs by some 10 per cent with the better diet and by 12-16 per cent with the diet containing only vegetable protein.

The antibiotics also improved food conversion; thus $3.72 \mathrm{lb} .( \pm 0.038)$ of the unsupplemented diet was needed to produce $1 \mathrm{lb}$. of live-weight gain, whereas the same gain required only $3.45 \mathrm{lb}$. $( \pm 0.038)$ food in the presence of penicillin and $3.49 \mathrm{lb} .( \pm 0.041)$ in the presence of aureomycin.

Trials under the Lehmann system are included in these averages. On their own they also indicated benefit from antibiotics.

In the grading, carcasses of pigs given the antibiotics were indistinguishable from the others, and treatment up to bacon-weight had therefore no effect on carcass quality.

For the trials with suckling pigs, more litters were needed than were available at the research stations. Farmers were therefore invited to co-operate, and thirteen of them, mainly breeders of pedigree pigs in south-west counties of England with a standard of management above the average, took part in the experiment. They either added the antibiotic supplement to their own creep meal, or used proprietary meals with the supplement in them. Two levels of aureomycin and two levels of procaine penicillin were tested. The piglets were weighed at birth and again at weaning. With 208 litters, the following weaning weights corrected to 63 days were obtained : aureomycin, $29 \mathrm{gm}$./ton, $43 \cdot 7 \mathrm{lb}$., $43 \mathrm{gm} . /$ ton, $40.5 \mathrm{lb}$; procaine penicillin, $7.5 \mathrm{gm}$./ton, $40 \cdot 1 \mathrm{lb}$., $15 \mathrm{gm}$./ton, $39 \cdot 3 \mathrm{lb}$.; control, no antibiotic,
$37 \cdot 7 \mathrm{lb}$. The results were very variable, probably owing to the wide difference of conditions on the farms. In consequence, the overall differences between treatments were not statistically significant and comparisons between individual treatments are not valid. The figures nevertheless suggest that some improvement in weight at weaning may have been produced by the antibiotics. The smaller dose of aureomycin gave the biggest apparent effect.

Taken as a whole, the results of tests carried out under the ægis of the Agricultural Research Council showed the usefulness of antibiotics in British pigfarming practice. They made it clear, however, that the extent of the benefit is influenced by a variety of factors, including method of feeding, management and health conditions on the farm. Thus the value of antibiotics can only be judged by their average performance in the country as a whole or on many farms, and not by individual effect or lack of effect in any separate trial.

The report emphasizes that many practical important aspects of the use of antibiotics in pig feeding with which the trials could not deal still require investigation. Thus the experiments were not designed to study the effects of adding vitamin $B_{12}$ with the antibiotic, and the alleged synergistic action of these substances will need to be studied. Nor did the trials extend over successive generations, and the benefit or harm of antibiotics to breeding stock should be given consideration in the future. Further work with suckling pigs is clearly needed, and the distinct possibility of beneficial use of antibiotics with runts must be explored.

Be that as it may, the trials showed that antibiotics have a place in British pig farming, and the findings of the report no doubt influenced the recent official decision about their use.

${ }^{1}$ Stokstad, E. L. R., and Jukes, T. H., Proc. Soc. Exp. Biol. Med., 73, 523 (1950). Poult. Sci., 29, 611 (1950). Jukes, T. H., Stokstad, Meadows, G. B., Arch. Biochem., 28, 324 (1950).

2 of. Braude, R., Kon, S. K., and Porter, J. W. G., Nutr. Abstr. Rev., 23, 473 (1953).

${ }^{3}$ Agricultural Research Council, A.R.C. Report Series No. 13, "Antibiotics in Pig Food". (H.M.S.O., London, 1953.)

\section{BRITISH COUNCIL ANNUAL REPORT FOR 1952-53}

THE nineteenth report of the British Council* covers the year ended March 31, 1953, in which its grant of $£ 2,527,100$ from United Kingdom public funds was 8.1 per cent less than during 1951-52. In connexion with the appointment of the Drogheda committee of inquiry into overseas information work, the Government announced that the 1952-53 level of activity would be maintained by the British Council, by the Government information serviues and by the overseas services of the B.B.C.; thus it is pointless, pending the results of this inquiry, to comment on the withdrawals from Persia and China, on the reduction of activity in Europe, and on the general disposition of the Council's resources as between Europe, the Middle East, Latin America and in the Commonwealth. It is understood that the Drogheda committee has now presented its report, but that the report is not to be published for security reasons. Publication of the findings, however, seems desirable in view of criticism of overseas

* Report on the Work of the British Council for the Year ended
31st March, 1953. Pp. v+105. (London: British Council, 1953.) 31st March, 1953. Pp. v+105. (London: British Council, 1953.)
2s. 6d. 